\title{
Tobacco Smoking: Findings from 20 Years of the Tehran Lipid and Glucose Study
}

\author{
Donna Parizadeh ${ }^{1}$, Amir Abbas Momenan ${ }^{1,{ }^{*}}$, Atieh Amouzegar ${ }^{1,2}$, Fereidoun Azizi ${ }^{1,2}$ and Farzad \\ Hadaegh ${ }^{1, * *}$ \\ ${ }^{1}$ Prevention of Metabolic Disorders Research Center, Research Institute for Endocrine Sciences, Shahid Beheshti University of Medical Sciences, Tehran, Iran \\ ${ }^{2}$ Endocrine Research Center, Research Institute for Endocrine Sciences, Shahid Beheshti University of Medical Sciences, Tehran, Iran \\ "Corresponding author: Prevention of Metabolic Disorders Research Center, Research Institute for Endocrine Sciences, Shahid Beheshti University of Medical Sciences, Tehran, \\ Iran. Email: momenan@endocrine.ac.ir \\ ${ }^{* *}$ Corresponding author: Prevention of Metabolic Disorders Research Center, Research Institute for Endocrine Sciences, Shahid Beheshti University of Medical Sciences, Tehran, \\ Iran. Email: fzhadaegh@endocrine.ac.ir
}

Received 2018 September 01; Revised 2018 October 02; Accepted 2018 October 07.

\begin{abstract}
Context: Smoking is a global public health priority and accurate data of the local population is essential to improve the health policies against its use. Hence, this study aimed to summarize the important findings available on the prevalence of smoking and its association with non-communicable diseases, documented by one of the largest prospective community-based studies of Iran. Evidence Acquisition: All articles derived from the Tehran Lipid and Glucose Study (TLGS) in the last two decades, from the earliest publications until 30 January 2018 were reviewed for their findings on tobacco smoking.

Results: The prevalence of smoking in non-diabetic adults $\geq 20$ years increased between baseline (phase I, 1999 - 2001) and followup (phase V, 2008 - 2011) from $25.5 \%$ to $35.4 \%$ among men and from $3.4 \%$ to $6.8 \%$ among women. In TLGS adolescents (10 - 18 years) water pipe use increased between 2003 and 2005 from 35.5\% to $40.9 \%$ among boys and from $19.7 \%$ to $26.1 \%$ among girls. Regarding health hazards, smoking in men was associated with increased risk of combined impaired fasting glucose/impaired glucose tolerance [hazard ratio (HR) 1.69; confidence interval (CI) 95\% 1.15 - 2.48] and hypertension (HR 1.26; CI 95\% 0.98 - 1.63). Moreover, men, even smoking less than 10 cigarettes per day, were at increased risk for cardiovascular diseases by HR 2.12 (CI 95\% 1.14 - 3.95). For women, the risk of chronic kidney disease dramatically increased 5.74-fold (CI 95\% 2.71 - 12.15) among smokers. In the whole population, smoking contributed to 7.7\% of all-cause mortality with HR 1.75 (CI 95\% 1.38 - 2.22). Other health aspects of tobacco smoke, including its impact on metabolic status, thyroid function, female reproductive system and life style have also been reviewed.

Conclusion: Considering hazards of smoking, there is the urgency for more effective preventive measures in Iran; emphasizing the need for further local studies on the hazards of smoking with special attention to women and adolescents and the independent hazards of water pipe use.
\end{abstract}

Keywords: Smoking, Tobacco, Cigarettes, Water Pipe, Prevalence, Risk

\section{Context}

Tobacco, known as the world's leading killer, is a major preventable disease risk factor (1). Smoking tobacco is responsible for the highest global disease burden, after high blood pressure (2). It can cause various noncommunicable diseases (NCDs) including about 25\% of ischemic heart events, $70 \%$ of chronic obstructive pulmonary diseases, and $90 \%$ of lung cancers (3).

In 2008, WHO issued a warning about the fatal tobacco epidemic, and predicted an increase in the annual tobaccorelated mortality from 5.4 million at the time, to 8 million by 2030 . More than $80 \%$ of the global burden of smoking is on low-to-middle income countries, where opposed to high-income countries, the prevalence of smoking is increasing. Unfortunately, these countries have limited resources to take preventive measures against tobacco use and are the main target of the tobacco industry (1). According to the sixth national survey of NCD Risk Factors Surveillance, in 2011, the rate of tobacco smoking in Iran was estimated to be about $10 \%$ among adults $19.2 \%$ in men and $0.6 \%$ in women), which was lower than most countries of the West and Middle East (4). Yet, despite various preventive measures Iran, the trend of smoking among adults has not decreased in the past two decades $(5,6)$. Moreover, the prevalence of smoking among adolescents seems to be increasing (7). According to the CASPIAN Study, in 2011 - 2012, 
$5.9 \%$ of the Iranian youth (aged 6 - 18 years) had smoked tobacco during their lives, which is higher than most Western and other Middle Eastern countries (4). Hence, a steep rise in the prevalence of smoking is expected in Iran, unless effective measures are implemented to prevent tobacco use. Raising awareness of the hazards of smoking is one of the most important steps of preventive programs (1), for which accurate local data on the risks of smoking is essential.

This review aimed to provide vital information on tobacco use and its risks, based on results from one of the largest cohort studies in Iran. Tehran Lipid and Glucose Study (TLGS) is an ongoing large scale and communitybased cohort, initiated in 1999 to help design and implement effective strategies against NCDs and their risk factors in a population of urban families from Tehran. During its years of investigation, the TLGS has documented valuable information about the prevalence, facilitators and hazards of smoking which have been summarized here.

\section{Evidence Acquisition}

Articles from the TLGS that were published or accepted for publication in a journal prior to 30 January 2018 and included data on tobacco use, were reviewed with the aim of providing a summary of the important findings of TLGS on smoking.

\section{Results}

\subsection{The Prevalence and Secular Trends of Smoking}

Data from the first phase of TLGS (1999 - 2001) revealed that among individuals aged $\geq 15$ years, $12 \%$ were smokers at the time (10.6\% daily smokers, $1.5 \%$ occasional smokers) and $6.1 \%$ were past smokers. The prevalence of smoking among women was as low as $2 \%$ compared to $22 \%$ among men which increased with aging in both genders, reaching a maximum of $4.3 \%$ among women and $38.1 \%$ among men at ages 35 to 44 years (8). Among the elderly (aged $>60$ years), we found a relatively lower rate of $17 \%$ in men and $2 \%$ in women, equal to an overall $10 \%$ among both genders. About $15 \%$ of the elderly population were past-smokers (9).

After a decade of follow-up, separate analyses for diabetic and non-diabetic adults revealed increase in smoking prevalence among TLGS women, from $3.17 \%$ to $4.95 \%$ for diabetics and from $3.39 \%$ to $6.82 \%$ for non-diabetics (10). The prevalence of smoking also increased among non-diabetic TLGS men, from $25.5 \%$ to $35.4 \%$ over a period of 10 years. For diabetic men, the rates increased from $20.18 \%$ to $24.23 \%$, but not significantly $($ Pvalue $=0.107)($ Figure 1$)(10)$. Among the elderly, smoking trends remained steady after a decade
(11). Regarding adolescents, a TLGS school survey in 2003 showed that $35.5 \%$ of boys and $19.7 \%$ of girls were current water pipe smokers according to the definition of Global Youth Tobacco Survey(GYTS), i.e. had smoked water pipe in the previous 30 days. The corresponding rates increased significantly after two years to $40.9 \%$ and $26.1 \%$, respectively (12).

Noting the unfavorable trends of smoking among the youth, the main facilitators of smoking were assessed among young men of TLGS, classifying the main effective factors into two categories including the personal motivators: (1) fulfilling essential needs, (2) search for identity, (3) lack of life skills, and the environmental factors: (1) social patterns (i.e. being impressed by smoker parents and peers), (2) ease of access (13).

\subsection{Smoking and Non-Communicable Diseases}

The findings of TLGS on the association of smoking with non-communicable diseases are summarized in this section. Moreover, details on studies with major clinical outcomes have been presented in Table 1.

\subsubsection{Pre-Hypertension and Hypertension}

Findings from the TLGS have shown that after a decade long follow-up, neither current nor past smoking was associated with increased risk of pre-hypertension (20). Furthermore, smoking was not associated with isolated systolic or diastolic hypertension after adjusting for other common risk factors (21). However, in an attempt to develop a point-score system to predict incident hypertension in nondiabetic individuals, Bozorgmanesh et al. indicated that smoking was independently associated with hypertension among men, to a marginally significant level (HR:1.26; CI 95\%: 0.98 -1.63), but they failed to find any associations for active or passive smoking among women (14).

\subsubsection{Pre-Diabetes and Type 2 Diabetes}

Regarding pre-diabetes phenotypes, after the important risk factors of family history of type 2 diabetes and fasting plasma glucose, current smoking had the highest hazard ratio (HR) for developing combined impaired fasting glucose/impaired glucose tolerance among men (HR: 1.69; CI 95\%: 1.15 - 2.48) (22). However, current smokers were not at increased risk for incident type 2 diabetes, neither among women nor among men, after almost a decade (15). More specifically, neither current, nor past smoking were associated with insulin resistance or $\beta$-cell dysfunction, as calculated by the HOMA-IR and HOMA-b formulas, respectively (23). Additionally, among TLGS adolescents, passive smoking was not associated with early adulthood pre-diabetes/type 2 diabetes (24). 

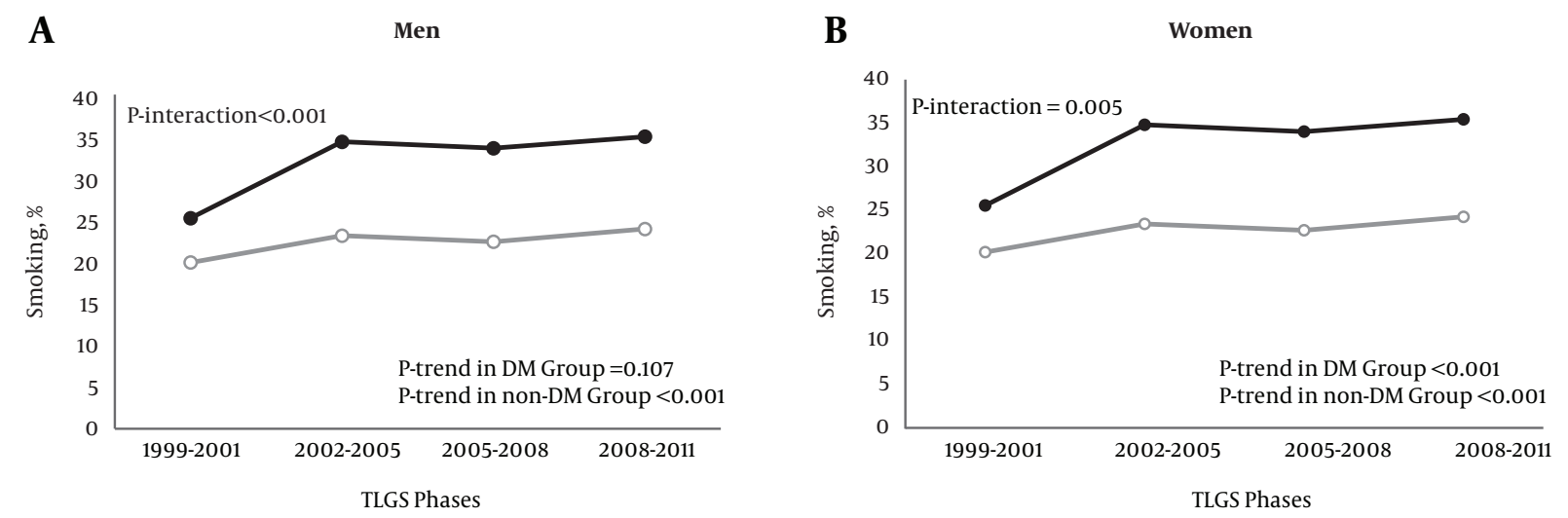

Figure 1. Age-adjusted prevalence of smoking among diabetic and non-diabetic men and women in phases I-IV of the TLGS. Age-adjusted prevalences of smoking for diabetic and non-diabetic men (A) and women (B) were derived from data presented by Jahangiri-Noudeh et al. (10). White circle = diabetic group; black circle = non-diabetic group; DM, diabetes mellitus; phase I (1999 - 2001), phase II (2002 - 2005), phase III (2005 - 2008), phase IV (2008 - 2012); TLGS, Tehran Lipid and Glucose Study.

\begin{tabular}{|c|c|c|c|c|c|c|}
\hline Study & Follow-Up, y & $\operatorname{Sex}(N)$ & Smoking Definition & Outcome & $\begin{array}{l}\text { Confounder } \\
\text { Adjustments }\end{array}$ & HR or OR(CI 95\%) \\
\hline $\begin{array}{l}\text { Bozorgmanesh et al. } \\
(14)\end{array}$ & 6 & $M(2695)$ & $\begin{array}{l}\text { Current smoker } \\
\text { (reference: Past/never } \\
\text { smoker) }\end{array}$ & Hypertension & $\begin{array}{l}\text { Age, SBP, DBP, FHCVD, } \\
\text { WC, age by SBP }\end{array}$ & $\begin{array}{c}\mathrm{HR}(\mathrm{M}): 1.26(0.98- \\
1.63)\end{array}$ \\
\hline $\begin{array}{l}\text { Derakhshan et al. } \\
\text { (15) }\end{array}$ & 9.5 & $\mathrm{M}(3620), \mathrm{F}(4780)$ & $\begin{array}{l}\text { Current smoker } \\
\text { (reference: Past/never } \\
\text { smoker) }\end{array}$ & Type 2 diabetes & None & $\begin{array}{l}\mathrm{HR}(\mathrm{M}): 0.97(0.75- \\
1.26), \mathrm{HR}(\mathrm{F}): 0.96 \\
(0.53-1.76)\end{array}$ \\
\hline Tohidi et al. (16) & 9.9 & $\mathrm{M}(1454), \mathrm{F}(1859)$ & $\begin{array}{l}\text { Current smoker } \\
\text { (reference: Never } \\
\text { smoker) }\end{array}$ & $\begin{array}{l}\text { Chronic kidney } \\
\text { disease }\end{array}$ & $\begin{array}{l}\text { Age, eGFR, diabetes } \\
\text { status, marital status, } \\
\text { HCVD, education, } \\
\text { hypertension, } \\
\text { dyslipidemia, } \\
\text { abdominal obesity, } \\
\text { BMI, FHCVD }\end{array}$ & $\begin{array}{c}\mathrm{OR}(\mathrm{M}) \text { : Not } \\
\text { applicable*, OR }(\mathrm{F}) \text { : } \\
5.74(2.71-12.15)\end{array}$ \\
\hline Khalili et al. (17) & 10.3 & $\mathrm{M}(2889), \mathrm{F}(3803)$ & $\begin{array}{l}\text { Current smoker } \\
\text { (reference: Past/never } \\
\text { smoker) }\end{array}$ & $\begin{array}{l}\text { Coronary heart } \\
\text { disease }\end{array}$ & $\begin{array}{l}\text { Age, FHCVD, } \\
\text { hypertension, } \\
\text { diabetes, total- } \\
\text { cholesterol, HDL-c }\end{array}$ & $\begin{array}{l}\mathrm{HR}(\mathrm{M}): 1.60(1.20- \\
2.0), \operatorname{HR}(\mathrm{F}): 1.20(0.6- \\
2.4)\end{array}$ \\
\hline Parizadeh et al. (18) & 12 & $M+F(3088)$ & $\begin{array}{l}\text { Current smoker } \\
\text { (reference: Past/never } \\
\text { smoker) }\end{array}$ & Ischemic stroke & $\begin{array}{l}\text { Age, sex, wrist } \\
\text { circumference, WC, } \\
\text { DBP, FPG, eGFR, } \\
\text { FHCVD }\end{array}$ & HR: $1.96(1.13-3.42)$ \\
\hline Sardarinia et al. (19) & 10.7 & $M+F(7635)$ & $\begin{array}{l}\text { Current smoker } \\
\text { (reference: Past/never } \\
\text { smoker) }\end{array}$ & Cardiovascular events & $\begin{array}{l}\text { Age, sex, BMI, } \\
\text { education, FHCVD }\end{array}$ & HR: $1.53(1.27-1.83)$ \\
\hline Sardarinia et al. (19) & 10.7 & $M+F(7635)$ & $\begin{array}{l}\text { Current smoker } \\
\text { (reference: Past/never } \\
\text { smoker) }\end{array}$ & All-cause mortality & $\begin{array}{l}\text { Age, sex, BMI, } \\
\text { education, FHCVD, } \\
\text { HCVD }\end{array}$ & HR:1.63 (1.29 - 2.06) \\
\hline
\end{tabular}

Abbreviations: BMI, body mass index; CI, confidence interval; DBP, diastolic blood pressure; eGFR, estimated glomerular filtration rate; FHCVD, family history of cardiovascular disease; FPG, fasting plasma glucose; HCVD, history of cardiovascular disease; HDL-c, high density lipoprotein cholesterol; HR, hazard ratio; OR, odds ratio; SBP; systolic blood pressure; $\mathrm{WC}$, waist circumference.

${ }^{a}$ Multivariate analysis not performed due to nonsignificant association in the univariate model.

\subsubsection{Chronic Kidney Disease}

Among the TLGS population, smoking was an independent risk factor for stages 3 - 5 of chronic kidney disease (CKD) in women which dramatically increased the risk about 6-fold for current smokers (HR: 5.74; CI 95\%: 2.71 - 12.15), but no longer remained significant among past smokers (HR: 1.67; CI 95\%: 0.66 - 4.22). However, no associations were found among men (16). 


\subsubsection{Metabolic Syndrome and Metabolic Risk Factors}

Regarding metabolic syndrome, smoking was not associated with increased risk among TLGS women or men (25); however, it has been shown to adversely affect the physical quality of life among TLGS men (26) In another TLGS investigation, Ramezankhani et al. applied the self-organizing map algorithm to cluster five metabolic risk factors (high body mass index (BMI), high systolic blood pressure, low glomerular filtration rate, high total-cholesterol and high fasting plasma glucose) and assess the corresponding risks of incident CVD. Surprisingly, smoking was significantly more prevalent among men in the healthier clusters and women who had quit smoking were assigned to the higher risk clusters. These findings may reflect the favorable effects of smoking on some metabolic risk factors, such as BMI or blood pressure (27); However, this does not overshadow the hazardous cardiovascular effects of smoking which are discussed as follows.

\subsubsection{Cardiovascular Diseases}

Smoking has been one of the conspicuous modifiable risk factors of CVD in the TLGS population. Almost 7.6\% of all CVD events were attributed to current smoking, increasing CVD risk by 61\% (19). In a detailed investigation among men, after adjustment for duration of smoking in addition to common CVD risk factors, current smoking showed an even stronger association with a hazard ratio of 2.12 (CI 95\%: 1.14 - 3.95) for smoking less than 10 cigarettes per day and 6.05 (CI 95\%: 2.83 - 12.92) for more than 20 cigarettes per day. The higher risk of CVD persisted after smoking cessation (HR: 2.42; CI 95\%: 1.28 - 4.56) (28). Current smoking also increased the risk of premature CVD among men (HR: 1.68; CI 95\%: 1.12 - 2.51) and was responsible for almost $20 \%$ of the events; however, the risk was nonsignificant among past smokers (29). Regarding coronary heart disease (CHD), after 10 years of follow-up, smoking (current or past) was the second most prevalent modifiable risk factor of CHD among men (HR: 1.6; CI 95\%: 1.2 - 2.0) with an average population attributable fraction (PAF) of $7 \%$; however, no significant risk was detected among women (17). In the detailed analysis among men, after adjustment for duration of smoking besides other risk factors, the HR ranged from 1.89 (CI 95\%: 0.96 - 3.7) for less than 10 cigarettes per day to 4.12 (CI 95\%: 1.75 - 9.71) for over 20 cigarettes per day among current smokers and the risk persisted among past smokers (HR: 1.64; CI 95\%: 0.81 - 3.35) (28). In another study with an extended follow-up of 12 years, past-smoking per se was associated with $83 \%$ increased risk of CHD (CI 95\%:1.30 - 2.59) (30). Of-course, regarding past smokers, the risk may disappear given more time. Also, in a comparison of smoking-related risk between diabetic and nondiabetic men, we demonstrated that diabetes did not al- ter the smoking-induced risk for CHD/CVD. Moreover, after twelve years of follow-up, smoking habits of nondiabetic men independently increased the risk for CHD and CVD by $49 \%$ and 53\%, respectively (P values < 0.001) (31). Regarding cerebrovascular events, the association between smoking and ischemic stroke was marginally significant after 9 years (HR: 1.73; CI 95\%: 0.97 - 3.08; PAF 14.5\%) (32), but grew stronger after 12 years of follow-up (HR: 1.96; CI 95\%: 1.13 3.42) (18). Lastly, in a cross-sectional investigation of cardiovascular risk factors in adolescents, smoking was associated with increased levels of total cholesterol $(\beta=0.11, \mathrm{P}$ value $=0.012)$ and $\operatorname{LDL}(\beta=0.4$, Pvalue $=0.001)$ among TLGS boys (33).

\subsection{Smoking and Mortality}

Results on all-cause mortality after over a decade long follow-up, indicated a hazard ratio of 1.75 (CI 95\%: 1.38 - 2.22) and a PAF of 7.71\% (CI 95\%: 3.85 - 11.54) for current smoking (19). An investigation launched on the TLGS type 2 diabetics pointed out that smoking (past/current) was associated with mortality among these patients with HR 1.45 (CI 95\%: 1.45 - 1.03) and PAF 11\% (34); However, an extended followup revealed that its association with mortality did not differ significantly between diabetic and non-diabetic men ( $P$ value $>0.46$ )(31). In another study, further analysis among men showed that the risk of mortality was attributed to the amount of daily cigarette smoking, independent of its duration. Regarding all-cause mortality, the association was only significant when smoking over 10 cigarettes per day, showing about four times higher risk, compared to non-smokers ( $\mathrm{P}$ value $<0.001$ ); whereas, the hazard ratio of CVD-mortality ranged from 4.57 (CI 95\%: 1.32 - 15.79) for smoking less than 10 cigarettes/day and dramatically increased to 12.06 (CI 95\%: 3.19 - 45.46) for more than 20 cigarettes/day. The association between smoking and mortality did not persist among past smokers (28).

\subsection{Smoking and the Female Reproductive System}

Smoking has been known to have anti-estrogenic effects on women (35). Among TLGS women, active smoking was associated with earlier menopause $($ P value $=0.05)(36)$ whereas passive smoking during childhood did not alter age of menarche (37). Regarding pathologies of the reproductive system, a cross-sectional analysis revealed that despite its relatively low prevalence, smoking was related to primary infertility in women (OR: 1.47; CI 95\%: 1.38 - 3.53) (38). For abnormal uterine bleeding, the increased hazard among smokers was not significant after multivariable adjustment $($ P value $=0.65)(39)$. 


\subsection{Smoking and Thyroid Function}

According to a cross-sectional observation of the euthyroid population of TLGS, after adjustment for age and BMI, the mean value of Ln TSH was significantly lower in current/past smokers, compared to non-smokers ( $0.36 \pm$ 0.82 vs. $0.6 \pm 0.82$; P value $<0.001)$ and the frequency of positive thyroperoxidase antibody was lower among current/past smokers compared to non-smokers (6.7\% vs. $13.5 \%$; P value $<0.001)$. Moreover, the prevalence of hypothyroidism (TSH $>5.8 \mathrm{mU} / \mathrm{L}$ ) was significantly lower among current/past smokers vs. non-smokers (OR 0.4; CI $95 \% 0.2-0.8$ ), but the prevalence of hyperthyroidism (TSH $<0.3 \mathrm{mU} / \mathrm{L}$ ) did not differ significantly between the two groups $(\mathrm{P}$ value $=0.28)(40)$. However, a recent longitudinal investigation on the natural course of euthyroidism among TLGS subjects revealed that after 6 years of followup, smoking was only associated with progression to overt hyperthyroidism $(\mathrm{TSH}<0.34 \mathrm{mU} / \mathrm{L}$ and serum free $\mathrm{T} 4>1.55$ $\mathrm{ng} / \mathrm{dL})(41)$.

\subsection{Smoking and Life Style}

Smokers among the TLGS population generally had a less healthy life style. As Asghari et al. demonstrated, smoking was more frequent among Tehranian adults with lower quality diets, judged by the Healthy eating index-2005 score (42). Moreover, cigarette smoking was associated with lower physical activity during leisure time among TLGS men (43).

\subsection{Smoking Water Pipe}

Although some of the TLGS articles have reported the hazards of water pipe use pooled with cigarette smoking, the risk caused independently by water pipe is still understudied. In one investigation, Ghasemi et al. assessed the effect of cigarette and water pipe smoking on the level of nitric oxide (NO) metabolites in serum and showed that both water pipe and cigarette smoking were associated with NO overproduction, which may be associated with further CVD risk (44).

\subsection{Response to Preventive Measures}

The first phase of the TLGS was a cross-sectional survey to investigate NCD and its risk factors. Following baseline data collection on phase I, lifestyle interventions were employed on a subgroup of individuals in follow-up phase II, with the aim to promote health. Smoking cessation was one of the three main arms of behavioral interventions, along with modifying nutrition and physical activity. Participants were educated and supported to stop smoking by a consultant through in-person consultations and relevant brochures, in a quit smoking clinic (45). After about
3.6 years, smoking cessation rate was $70 \%$ higher in the intervention group compared to the control group (P value $=0.01)(46)$.

\section{Discussion}

This study summarizes the key findings of the TLGS on the prevalence, facilitators and long-term hazards of smoking tobacco in a community representing the general population of Tehran. Overall, we highlighted the role of tobacco smoking as a major risk factor for CVD, CHD, ischemic stroke, CKD, hypertension and mortality in an Iranian population. Smoking also affected thyroid function tests and the female reproductive system.

Despite the TLGS life style interventions aimed at smoking prevention, the overall prevalence of smoking has not decreased in the last two decades. More importantly, the increasing trends of smoking among women and the high and rising prevalence of water pipe use among adolescents, are alarming signs for higher smoking rates in the future. In general, in line with national surveys $(5,6)$, smoking rates at baseline were lower among TLGS women compared to western countries as estimated in the recent global reports of WHO (4), which could be attributed to the less social acceptability of smoking for women in Iran. However, a rise of female smokers was noticed in the previous decade which was higher in the TLGS compared to a simultaneous national systematic review that included reports from several cities of Iran, besides Tehran (6). The difference between surveys is not surprising, since there are generally less social limits on women in Tehran compared to other cities of Iran. Regarding adolescents, the prevalence of using tobacco products other than cigarettes (mostly in the form of water pipes) in the GYTS report of 1999 - 2001 was considerably lower in European and other Middle Eastern regions (all rates below 15\%), compared to the TLGS (47). This may be attributed to the traditional aspect of water pipe use in Iran which has made it more socially acceptable (48). Overall, these findings indicate that preventive programs against smoking need to be upgraded in Iran. According to the WHO report on the national tobacco control program, evaluated by the MPOWER measures, Iran has performed well in many aspects of smoking control including smoke-free policies, smoking cessation programs, health warnings on cigarette packages, anti-tobacco campaigns and bans on advertising for tobacco use. However, taxation, which is considered the most effective way to discourage smoking, has been overlooked in our country (49).

The strengths of this study are that it summarizes the findings of community-based investigations with longterm follow-ups, derived from one of the largest cohort 
studies in the Middle East and the results are not derived from a specific population (e.g. students), unlike many other local studies on smoking (6). In addition, all of the included studies have used a unified definition for smoking habits according to the WHO guidelines (50). There are also some limitations. Firstly, due to the low prevalence of smoking, many of the studies could not report on the hazards of smoking among women. Secondly, although in many studies smoking was attributed to all forms of smoked tobacco including water pipe, data on the independent hazards of water pipes are lacking, which is particularly important due to the popularity this form of tobacco use in Iran (48). In addition, data on smoking status were based on self-reports and no paraclinical assessments, such as serum cotinine levels, had been obtained, which may lead to underestimation of smoking rates, since there is a negative attitude in our culture towards smoking, especially for women. In this regard, comparing results of serum cotinine levels with the corresponding self-reports, Sarraf-Zadegan et al. reported a significant rise in rates of tobacco use $(10.6 \%$ rise among men and $14.6 \%$ rise among women) (51). However, to reduce the bias, interviews in the TLGS were performed in a private setting and women have been questioned by female interviewers. Moreover, since most studies have considered smoking as a binary variable, they lack information on the duration and intensity of smoking or the time passed from smoking cessation. Lastly, although most studies made adjustments for a wideset of variables, further adjustments could alter the associations, e.g. life style interventions and nutrition could affect NO levels in serum in the study by Ghasemi et al. (44).

\subsection{Conclusion}

Considering the various health hazards which have been summarized in the current study, smoking should remain a priority in public health policies. In order to improve preventive measures, future studies are required to determine the impact of population-based interventions against smoking. In addition, more attention must be focused on smoking among women and adolescents and the hazards of other types of tobacco use, such as water pipe.

\section{Acknowledgments}

The authors would like to express appreciations to the investigators and participants of the TLGS for their cooperation. The authors also wish to acknowledge Ms. Niloofar Shiva for critical editing of English grammar and syntax of the manuscript.

\section{References}

1. World Health Organization. Report on the global tobacco epidemic 2008. The MPOWER package. 2008. Available from: http://www.who. int/tobacco/mpower/mpower_report_full_2008.pdf.

2. Lim SS, Vos T, Flaxman AD, Danaei G, Shibuya K, Adair-Rohani H, et al. A comparative risk assessment of burden of disease and injury attributable to 67 risk factors and risk factor clusters in 21 regions, 1990-2010: A systematic analysis for the global burden of disease study 2010. Lancet. 2012;380(9859):2224-60. doi: 10.1016/S01406736(12)61766-8. [PubMed: 23245609]. [PubMed Central: PMC4156511].

3. Mackay J EM. The tobacco Atlas. Geneva: World Health Organization; 2002.

4. World Health Organization. WHO report on the global tobacco epidemic. 2017. Available from: http://www.who.int/tobacco/global_ report/2017/appendix_II.pdf?ua=1.

5. Meysamie A, Ghaletaki R, Haghazali M,Asgari F, Rashidi A, Khalilzadeh $\mathrm{O}$, et al. Pattern of tobacco use among the Iranian adult population: Results of the national survey of risk factors of noncommunicable diseases (SuRFNCD-2007). Tob Control. 2010;19(2):1258. doi: 10.1136/tc.2009.030759. [PubMed: 20008159]. [PubMed Central: PMC2989156].

6. Halimi L, Haghdoost AA, Mohammad Alizadeh S. Prevalence of cigarette smoking among Iranian women: A systematic review and meta-analysis. Med J Islam Repub Iran. 2013;27(3):132-40. [PubMed: 24791123]. [PubMed Central: PMC3917490].

7. Mohammad-Alizadeh-Charandabi S, Mirghafourvand M, Tavananezhad N, Karkhaneh M. Prevalence of cigarette and water pipe smoking and their predictors among Iranian adolescents. Int J Adolesc Med Health. 2015;27(3):291-8. doi: 10.1515/ijamh-2014-0028. [PubMed: 25470603].

8. Azizi F, Rahmani M, Emami H, Mirmiran P, Hajipour R, Madjid M, et al. Cardiovascular risk factors in an Iranian urban population: Tehran Lipid and Glucose Study (phase 1). Soz Praventivmed. 2002;47(6):40826. [PubMed: 12643001].

9. Azizi F, Emami H, Salehi P, Ghanbarian A, Mirmiran P, Mirbolooki $\mathrm{M}$, et al. Cardiovascular risk factors in the elderly: The Tehran Lipid and Glucose Study. J Cardiovasc Risk. 2003;10(1):65-73. doi: 10.1097/01.hjr.0000050202.47754.1b. [PubMed:12569239].

10. Jahangiri-Noudeh Y, Akbarpour S, Lotfaliany M, Zafari N, Khalili D, Tohidi M, et al. Trends in cardiovascular disease risk factors in people with and without diabetes mellitus: A Middle Eastern cohort study. PLoS One. 2014;9(12). e112639. doi: 10.1371/journal.pone.0112639. [PubMed: 25461381]. [PubMed Central: PMC4251920].

11. Eslami A, Lotfaliany M, Akbarpour S, Azizi F, Hadaegh F. Trend of cardiovascular risk factors in the older Iranian population: 2002-2014. Geriatr Gerontol Int. 2018;18(1):130-7. doi: 10.1111/ggi.13154. [PubMed: 28857406]

12. Momenan AA, Etemadi A, Ghanbarian A, Azizi F . The rising prevalence of waterpipe smoking among Iranian adolescents: Tehran Lipid and Glucose Study. Proceedings of the 13th World Congress on Tobacco OR Health (WCTOH). Washington, DC, USA. 2006.

13. Rostami Dovom M, Ramezani Tehrani F, Amiri P, Amirshekari G, Farahmand M, Azizi F. Main facilitators of smoking among young males in tehran: Tehran Lipid and Glucose Study. Iran Red Crescent Med J. 2014;16(9). e15429. doi: 10.5812/ircmj.15429. [PubMed: 25593726]. [PubMed Central: PMC4270672].

14. Bozorgmanesh M, Hadaegh F, Mehrabi Y, Azizi F. A point-score system superior to blood pressure measures alone for predicting incident hypertension: Tehran Lipid and Glucose Study. J Hypertens. 2011;29(8):1486-93. doi: 10.1097/HJH.0b013e328348fdb2. [PubMed: 21720268].

15. Derakhshan A, Sardarinia M, Khalili D, Momenan AA, Azizi F, Hadaegh F. Sex specific incidence rates of type 2 diabetes and its risk factors over 9 years of follow-up: Tehran Lipid and Glucose Study. PLoS One. 2014;9(7). e102563. doi: 10.1371/journal.pone.0102563. [PubMed: 25029368]. [PubMed Central: PMC4100911]. 
16. Tohidi M, Hasheminia M, Mohebi R, Khalili D, Hosseinpanah F, Yazdani B, et al. Incidence of chronic kidney disease and its risk factors, results of over 10 year follow up in an Iranian cohort. PLoS One. 2012;7(9). e45304. doi: 10.1371/journal.pone.0045304. [PubMed: 23028919]. [PubMed Central: PMC3459968].

17. Khalili D, Sheikholeslami FH, Bakhtiyari M, Azizi F, Momenan AA, Hadaegh F. The incidence of coronary heart disease and the population attributable fraction of its risk factors in Tehran: A 10-year population-based cohort study. PLoS One. 2014;9(8). e105804. doi: 10.1371/journal.pone.0105804. [PubMed: 25162590]. [PubMed Central: PMC4146560].

18. Parizadeh D, Ramezankhani A, Momenan AA, Azizi F, Hadaegh F. Exploring risk patterns for incident ischemic stroke during more than a decade of follow-up: A survival tree analysis. Comput Methods Programs Biomed. 2017;147:29-36. doi: 10.1016/j.cmpb.2017.06.006. [PubMed: 28734528].

19. Sardarinia M, Akbarpour S, Lotfaliany M, Bagherzadeh-Khiabani F, Bozorgmanesh M, Sheikholeslami F, et al. Risk factors for incidence of cardiovascular diseases and all-cause mortality in a middle eastern population over a decade follow-up: Tehran Lipid and Glucose Study. PLoS One. 2016;11(12). e0167623. doi: 10.1371/journal.pone.0167623. [PubMed: 27930696]. [PubMed Central: PMC5145170].

20. Hadaegh F, Hasheminia M, Abdi H, Khalili D, Bozorgmanesh M, Arshi B, et al. Prehypertension tsunami: A decade follow-up of an iranian adult population. PLoS One. 2015;10(10). e0139412. doi: 10.1371/journal.pone.0139412. [PubMed: 26439847]. [PubMed Central: PMC4595371].

21. Asgari S, Khalili D, Mehrabi Y, Kazempour-Ardebili S, Azizi F, Hadaegh F. Incidence and risk factors of isolated systolic and diastolic hypertension: A 10 year follow-up of the Tehran Lipids and Glucose Study. Blood Press. 2016;25(3):177-83. doi: 10.3109/08037051.2015.1116221. [PubMed: 26643588].

22. Hadaegh F, Derakhshan A, Zafari N, Khalili D, Mirbolouk M, Saadat N, et al. Pre-diabetes tsunami: Incidence rates and risk factors of prediabetes and its different phenotypes over 9 years of follow-up. Diabet Med. 2017;34(1):69-78. doi:10.1111/dme.13034. [PubMed: 26606421].

23. Derakhshan A, Tohidi M, Hajebrahimi MA, Saadat N, Azizi F, Hadaegh F. Sex-specific incidence rates and risk factors of insulin resistance and beta-cell dysfunction: A decade follow-up in a Middle Eastern population. Diabet Med. 2017;34(2):245-52. doi: 10.1111/dme.13117. [PubMed: 26996519].

24. Mirbolouk M, Derakhshan A, Charkhchi P, Guity K, Azizi F, Hadaegh F. Incidence and predictors of early adulthood pre-diabetes/type 2 diabetes, among Iranian adolescents: The Tehran Lipid and Glucose Study. Pediatr Diabetes. 2016;17(8):608-16. doi: 10.1111/pedi.12343. [PubMed: 26764014].

25. Hadaegh F, Hasheminia M, Lotfaliany M, Mohebi R, Azizi F, Tohidi $M$. Incidence of metabolic syndrome over 9 years followup; the importance of sex differences in the role of insulin resistance and other risk factors. PLoS One. 2013;8(9). e76304. doi: 10.1371/journal.pone.0076304. [PubMed: 24086723]. [PubMed Central: PMC3785433].

26. Amiri P, Deihim T, Taherian R, Karimi M, Gharibzadeh S, AsghariJafarabadi M, et al. Factors affecting gender differences in the association between health-related quality of life and metabolic syndrome components: Tehran Lipid and Glucose Study. PLoS One. 2015;10(12). e0143167. doi: 10.1371/journal.pone.0143167. [PubMed: 26625120]. [PubMed Central: PMC4666460].

27. Ramezankhani A, Azizi F, Hadaegh F, Eskandari F. Sexspecific clustering of metabolic risk factors and their association with incident cardiovascular diseases: A populationbased prospective study. Atherosclerosis. 2017;263:249-56. doi: 10.1016/j.atherosclerosis.2017.06.921. [PubMed: 28683364].

28. Ehteshami-Afshar S, Momenan A, Hajshekholeslami F, Azizi F, Hadaegh F. The impact of smoking status on 9.3 years incidence of cardiovascular and all-cause mortality among Iranian men. Ann Hum
Biol. 2014;41(3):249-54. doi: 10.3109/03014460.2013.853834. [PubMed: 24215537].

29. Eslami A, Mozaffary A, Derakhshan A, Azizi F, Khalili D, Hadaegh F. Sex-specific incidence rates and risk factors of premature cardiovascular disease. A long term follow up of the Tehran Lipid and Glucose Study. Int J Cardiol. 2017;227:826-32. doi: 10.1016/j.ijcard.2016.10.037. [PubMed: 27829526].

30. Ramezankhani A, Bagherzadeh-Khiabani F, Khalili D, Azizi F, Hadaegh F. A new look at risk patterns related to coronary heart disease incidence using survival tree analysis: 12 years longitudinal study. Sci Rep. 2017;7(1):3237. doi: 10.1038/s41598-017-03577-0. [PubMed: 28607472]. [PubMed Central: PMC5468345].

31. Hadaegh F, Derakhshan A, Mozaffary A, Hasheminia M, Khalili D, Azizi F. Twelve-year cardiovascular and mortality risk in relation to smoking habits in type 2 diabetic and non-diabetic men: Tehran Lipid and Glucose Study. PLoS One. 2016;11(3). e0149780. doi: 10.1371/journal.pone.0149780. [PubMed: 26930192]. [PubMed Central: PMC4773225].

32. Fahimfar N, Khalili D, Mohebi R, Azizi F, Hadaegh F. Risk factors for ischemic stroke; results from 9 years of follow-up in a population based cohort of Iran. BMC Neurol. 2012;12:117. doi: 10.1186/1471-2377-12117. [PubMed: 23031547]. [PubMed Central: PMC3517457].

33. Azizi F, Mirmiran P, Azadbakht L. Predictors of cardiovascular risk factors in Tehranian adolescents: Tehran Lipid and Glucose Study. Int J Vitam Nutr Res. 2004;74(5):307-12. doi: 10.1024/0300-9831.74.5.307. [PubMed: 15628667].

34. Afsharian S, Akbarpour S, Abdi H, Sheikholeslami F, Moeini AS, Khalili D, et al. Risk factors for cardiovascular disease and mortality events in adults with type 2 diabetes - a 10-year follow-up: Tehran Lipid and Glucose Study. Diabetes Metab Res Rev. 2016;32(6):596-606. doi: 10.1002/dmrr.2776. [PubMed: 26787367].

35. Baron JA, La Vecchia C, Levi F. The antiestrogenic effect of cigarette smoking in women. Am J Obstet Gynecol. 1990;162(2):502-14. doi: 10.1016/0002-9378(90)90420-C. [PubMed: 2178432].

36. Farahmand M, Tehrani FR, Pourrajabi L, Najafi M, Azizi F. Factors associated with menopausal age in Iranian women: Tehran Lipid and Glucose Study. J Obstet Gynaecol Res. 2013;39(4):836-41. doi: 10.1111/j.14470756.2012.02050.x. [PubMed: 23279558].

37. Ramezani Tehrani F, Mirmiran P, Gholami R, Moslehi N, Azizi F. Factors influencing menarcheal age: results from the cohort of Tehran Lipid and Glucose Study. Int J Endocrinol Metab. 2014;12(3). e16130. doi: 10.5812/ijem.16130. [PubMed: 25237321]. [PubMed Central: PMC4166004].

38. Kazemijaliseh H, Ramezani Tehrani F, Behboudi-Gandevani S, Hosseinpanah F, Khalili D, Azizi F. The prevalence and causes of primary infertility in Iran: A population-based study. Glob J Health Sci. 2015;7(6):226-32. doi: 10.5539/gjhs.v7n6p226. [PubMed: 26153187]. [PubMed Central: PMC4803880].

39. Kazemijaliseh H, Ramezani Tehrani F, Behboudi-Gandevani S, Khalili D, Hosseinpanah F, Azizi F. A population-based study of the prevalence of abnormal uterine bleeding and its related factors among Iranian reproductive-age women: An updated data. Arch Iran Med. 2017;20(9):558-63. [PubMed: 29048917].

40. Mehran L, Amouzgar A, Delshad H, Azizi F. The association of cigarette smoking with serum TSH concentration and thyroperoxidase antibody. Exp Clin Endocrinol Diabetes. 2012;120(2):80-3. doi: 10.1055/s-0031-1285910. [PubMed: 21915816].

41. Amouzegar A, Ghaemmaghami Z, Beigy M, Gharibzadeh S, Mehran L, Tohidi M, et al. Natural course of euthyroidism and clues for early diagnosis of thyroid dysfunction: Tehran Thyroid Study. Thyroid. 2017;27(5):616-25. doi: 10.1089/thy.2016.0409. [PubMed: 28071990].

42. Asghari G, Mirmiran P, Hosseni-Esfahani F, Nazeri P, Mehran M, Azizi F. Dietary quality among Tehranian adults in relation to lipid profile: findings from the Tehran Lipid and Glucose Study. J Health Popul Nutr. 2013;31(1):37-48. doi: 10.3329/jhpn.v31i1.14747. [PubMed: 
23617203]. [PubMed Central: PMC3702357].

43. Momenan AA, Delshad M, Mirmiran P, Ghanbarian A, Azizi F. Leisure time physical activity and its determinants among adults in Tehran: Tehran Lipid and Glucose Study. Int J Prev Med. 2011;2(4):243-51. [PubMed: 22174964]. [PubMed Central: PMC3237267].

44. Ghasemi A, Syedmoradi L, Momenan AA, Zahediasl S, Azizi F. The influence of cigarette and qalyan (hookah) smoking on serum nitric oxide metabolite concentration. Scand J Clin Lab Invest. 2010;70(2):116-21. doi: 10.3109/00365511003611282. [PubMed: 20156035].

45. Azizi F, Ghanbarian A, Momenan AA, Hadaegh F, Mirmiran P, Hedayati $\mathrm{M}$, et al. Prevention of non-communicable disease in a population in nutrition transition: Tehran Lipid and Glucose Study phase II. Trials. 2009;10:5. doi: 10.1186/1745-6215-10-5. [PubMed: 19166627]. [PubMed Central: PMC2656492].

46. Harati H, Hadaegh F, Momenan AA, Ghanei L, Bozorgmanesh MR, Ghanbarian A, et al. Reduction in incidence of type 2 diabetes by lifestyle intervention in a middle eastern community. Am J Prev Med. 2010;38(6):628-636 e1. doi: 10.1016/j.amepre.2010.03.003. [PubMed: 20494239].
47. Global Youth Tabacco Survey Collaborative G. Tobacco use among youth: A cross country comparison. Tob Control.2002;11(3):252-70. doi 10.1136/tc.11.3.252. [PubMed:12198280]. [PubMed Central: PMC1759013]

48. Kelishadi R, Ardalan G, Gheiratmand R, Majdzadeh R, Delavari A Heshmat R, et al. Smoking behavior and its influencing factors in a national-representative sample of Iranian adolescents: CASPIAN Study. Prev Med. 2006;42(6):423-6. doi: 10.1016/j.ypmed.2006.03.001. [PubMed: 16624397].

49. World Health Organization. WHO report on the global tobacco epidemic, 2017. Country profile Iran (Islamic Republic of). 2017. Available from: http://www.who.int/tobacco/surveillance/policy/country_ profile/irn.pdf.

50. World Health Organization. Guideline for controlling and monitoring The Tobacco Epidemic. 1998. Available from: http://www.who.int/iris/ handle/10665/42049.

51. Sarraf-Zadegan N, Boshtam M, Shahrokhi S, Naderi GA, Asgary S, Shahparian $\mathrm{M}$, et al. Tobacco use among Iranian men, women and adolescents. Eur J Public Health. 2004;14(1):76-8. doi: 10.1093/eurpub/14.1.76. [PubMed: 15080396] 